\title{
Por fin fue la lagartija roja la que habló
}

\section{Artículo de investigación}

\section{Álvaro Andrés Corredor}

Universidad Distrital Francisco José de Caldas,

Colombia

andresco1@yahoo.com

Recibido: 20 de septiembre de 2019

Aprobado: 28 de octubre de 2019

Cómo citar este artículo: Corredor, Álvaro Andrés (2020). Por fin fue la lagartija roja la que habló. Calle 14: revista de investigación en el campo del arte 15(28).

pp. 306-321. https://doi.org/10.14483/21450706.16271

\section{(2) (1)}

https://creativecommons.org/licenses/by/4.0/deed.es 


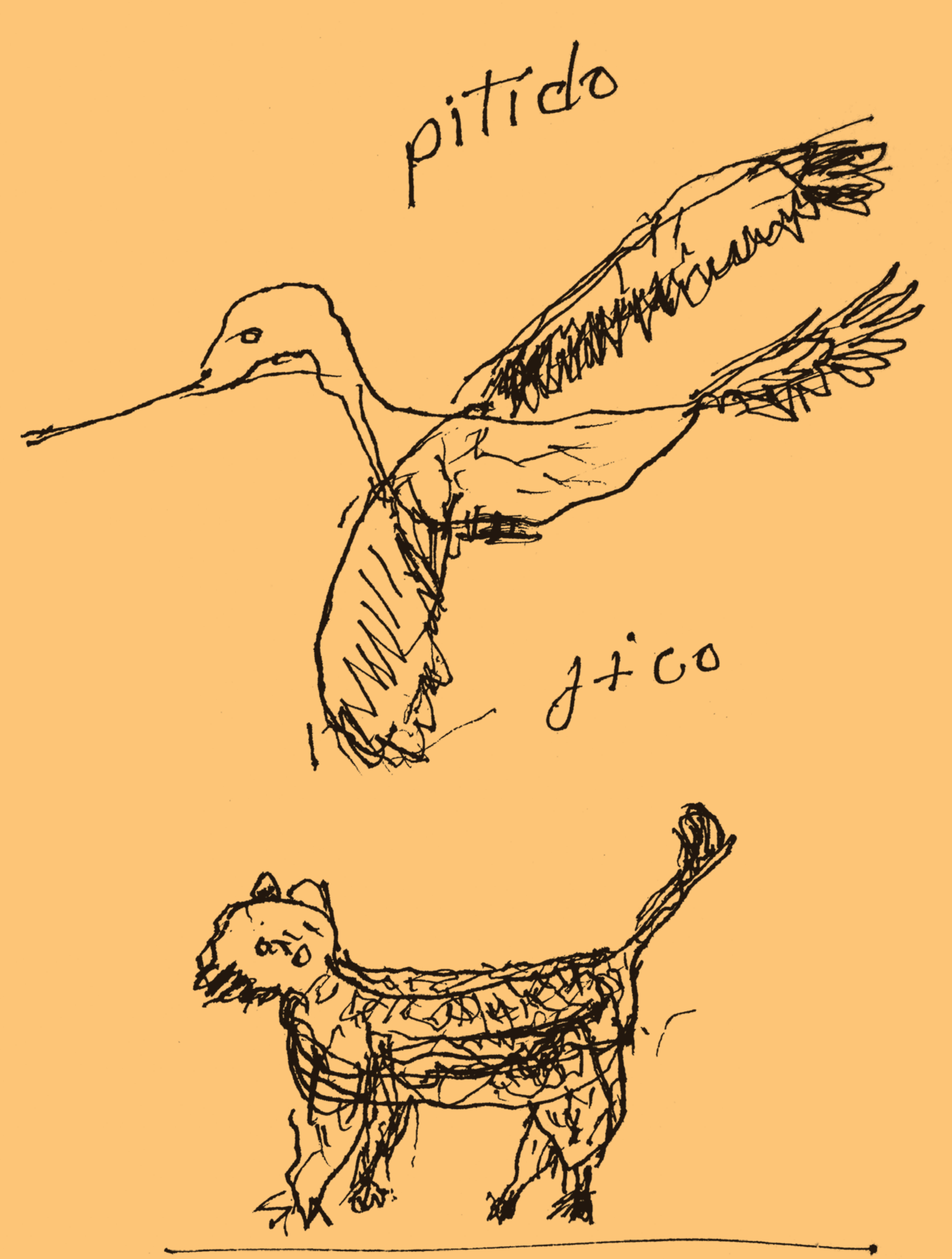




\title{
Resumen
}

La resistencia de los pueblos y sistemas de pensamiento que han sido colonizados en lo sensible por la hegemonía del sistema-mundo moderno colonial, genera un escenario de alternativas epistémicas diferenciales frente a los patrones eurocentrados en esta materia, revelando un conjunto de posicionamientos "otros" en lo sensible, que asumen modos autónomos de entender las ideas de conocimiento, sensibilidad, el sentido del conocer y las formas de relación entre quienes se comprometen en tales procesos. El pensamiento uitoto, que en su concepto del "saber enfrentar la vida" asume la existencia humana en armonía con el conjunto de la vida en el tejido-mundo -mediante el equilibrio con las fuerzas vitales, el reconocimiento mutuo entre las gentes (humanas y no humanas) y la relación comunitaria en los ámbitos personales, sociales, políticos y cósmicos-, señala entre los conceptos asociados al conocimiento-sensible: el medir la mano, el fortalecer el manejo de los aires de aliento y el encontrar el propio cuerpo

\section{Palabras clave}

Conocimiento; sensibilidad; interculturalidad; pueblo uitoto; descolonización.

\section{Finally, it Was the Red Lizard that Spoke}

\begin{abstract}
The resistance of the peoples and systems of thought that have been colonized in their senses by the hegemony of the modern colonial world-system, generates a scenario of differential epistemic alternatives vis-à-vis the Euro-centered patterns in this matter, revealing a set of «other» positions in the sensory dimension. The latter assume autonomous ways of understanding the ideas of knowledge, sensitivity, the sense of knowing and the forms of relationship between those who engage in such processes. The Uitoto way of thinking, which, in its concept of «knowing how to face life» assumes a human existence that is in harmony with the whole of life in the world-fabric - through balance with vital forces, mutual recognition between people (human and non-human) and the community relationship in the personal, social, political and cosmic spheres -, and points to several concepts associated with sensitive-knowledge: measuring the hand, strengthening the handling of breathing and finding one's own body
\end{abstract}

\section{Keywords}

Knowledge; sensitivity; interculturality; Uitoto people; decolonization.

\section{Enfin, c'est le Lézard Rouge qui a parlé}

\section{Résumé}

La résistance des peuples et des systèmes de pensée colonisés par l'hégémonie du systèmemonde colonial moderne sur les sens, génère un scénario d'alternatives épistémiques différentielles vis-à-vis des schémas euro-centrés en la matière, révélant un ensemble de positions «autres» dans la dimension sensorielle. Ces derniers supposent des manières autonomes de comprendre les idées de connaissance, de sensibilité, le sens du savoir et les formes de relation entre ceux qui s'engagent dans de tels processus. La façon de penser Uitoto, qui, dans son concept de «savoir faire face à la vie» suppose une existence humaine en harmonie avec l'ensemble de la vie dans le tissu-monde - par l'équilibre avec les forces vitales, la reconnaissance mutuelle entre les personnes (humaines et non-humaines) et la relation communautaire dans les sphères personnelle, sociale, politique et cosmique -, et pointe vers plusieurs concepts associés à la connaissance sensible: mesurer la main, renforcer la manipulation de la respiration et trouver son propre corps 


\section{Mots clés}

Connaissance ; sensibilité ; l'interculturalité ; Uitotos ; décolonisation.

Por fim foi a lagartixa Vermelha, a que falou

\section{Resumo}

A resistência dos povos e sistemas de pensamento que foram colonizados no sensível pela hegemonia do sistema-mundo moderno colonial, gera um cenário de alternativas epistêmicas diferenciais diante aos padrões eurocentrados nesta matéria, revelando um conjunto de posicionamentos "outros" no sensível, que assumem modos autônomos de entender as ideias de conhecimento, sensibilidade, o sentido do conhecer e as formas de relação entre quem se compromete com tais processos. O pensamento Uitoto que em seu conceito do "saber enfrentar a vida" assume a existência humana na harmonia com o conjunto da vida no tecido-mundomediante o equilíbrio com as forças vitais, o conhecimento mútuo entre os seres (humanos e não humanos) e a relação comunitária nos âmbitos pessoais, sociais, políticos e cósmicos -, aponta entre os conceitos associados ao conhecimento-sensível: o medir a mão, o fortalecer o manusear dos ares de respiração e o encontrar o próprio corpo.

\section{Palavras chave}

Conhecimento; sensibilidade; interculturalidade; Uitoto; descolonização.

\section{Maituku unaipi rimarispa Puka alpapi aliuridur}

\section{Maillallachiska}

Munakumi ningapa imasami sinchillalliku runakunapa kausai iuiai mana sugkuna challamuspa iachachichikuna mana kaskasina mukanchi llukaschi mana chingachinga nukunchi kaska uitato iuiarii ninakumi paikunamanda kansi iaichaiku imasapas kausangapa nukanchi kaipikauramanda llukanchi ñugpasinama kawaspa katichinakunga nispa chimanda nukanchi llukanchi maipipas kawaringa maki kuanakuspa kusnita allilla kawaspa chasallata nukanchimanda iuiarispa.

\section{Rimangapa Ministidukuna}

Iachaska; Nana llapa muruchu; kawachii nukanchi kaska; chasa sutikuna; sug sinama katichii. 
Abordar y resolver una intención investigativa, planteada desde el escenario de las prácticas del arte en el ámbito de la universidad occidental, respecto a elementos y modos de lo sensible, configurados en otros sistemas de pensamiento - no academizados por la institución universitaria o no occidentales-, nos confronta con notorias tensiones diferenciales en lo relativo a los intereses del conocer, a los modos de relación entre los sujetos que conocen, a la noción de conocimiento y a los modos del conocer que se activan en este propósito. Estas diferencias, en el caso de América Latina, además de reflejar la heterogeneidad de las visiones de mundo entre sus gentes, sus tradiciones culturales y sus modos del vivir, se constituyen en soporte de relaciones de exclusión y dominación por parte de las formas eurocéntricas de conocimiento (Grosfóguel, 2007, p. 9), que han operado en el continente a lo largo de los últimos cinco siglos.

\section{De la colonialidad del poder a la colonialidad en lo sensible}

Según Quijano y Dussel, el eurocentrismo es una actitud colonial respecto al conocimiento que sostiene la aparición y afianzamiento de la colonialidad del poder en el marco del sistema-mundo moderno. ${ }^{1}$ En ello, articula simultáneamente "las relaciones centro-periferia y las jerarquías étnico/raciales" (Grosfóguel, 2007, p. 20.), para soportar la concepción del conocimiento europeo como superioridad irrebatible por sobre toda otra configuración del saber — como son las maneras no europeas del conocer y del vivir-, sosteniendo la aparición y afianzamiento de la colonialidad del poder.

Wallerstein entiende por sistema-mundo moderno al marco
histórico que, siendo una consecuencia de la economía mundial capi-
talista, se ha estructurado sobre un sistema de división única mundial
del trabajo; implica una ideología del universalismo aplicada en el
sistema interestatal y laimposición de instituciones, teorías, conven-
ciones, valores y medidas universales. Se articula a partir de princi-
pios de exclusión y dominación de carácter racista y sexista para el
mantenimiento de jerarquías, desigualdades e inferiorizaciones, tanto
desde el punto de vista genético como cultural, entre los estados y
los ciudadanos. Tales inferiorizaciones son entendidas como verdades
eternas, únicamente modificadas por el proceso de la "educación" a
largo plazo, justificando los procesos de modernización, el proseli-
tismo cristiano y la misión civilizatoria. Puesto que el sistema-mundo
moderno declara a la cultura occidental como universal, impone los
principios universales de la ciencia y su racionalidad dominante sobre
otras racionalidades no-modernas. (Wallerstein citado en Castro-
Gómez, 1999, pp. 167-181).

En su planteamiento sobre la colonialidad del poder, Quijano señala dos aspectos capitales para su funcionamiento y consolidación: "la dependencia histórico-estructural y la hegemonía del eurocentrismo como perspectiva de conocimiento" (Quijano, 1999, pp. 103104). Así, entiende que la aparición de la colonialidad del poder en América se establece sobre una relación de dominación de los colonizadores sobre los colonizados, construida sobre una idea de "raza" desde la que los colonizadores imponen identidades adversas para la autonomía e intereses de las poblaciones originarias del continente quienes son definidas como "indios", de modo similar a las poblaciones procedentes de distintas naciones del África, quienes llegan a América en condición de esclavización y que son declaradas "negros". Es en el proceso de generación y consolidación del estatuto de superioridad racial de los colonizadores, que estos inicialmente se autodenominan como "ibéricos", "españoles", "portugueses", "británicos", etc.; y que no es sino hasta las postrimerías del siglo XVIII que se presentan como "europeos" o "blancos". A partir de entonces, los descendientes de las relaciones entre colonos y colonizados serán denominados como mestizos, conformando identidades funcionales para una clasificación social que ha servido de soporte a distintas formas de explotación del trabajo y de las relaciones de género. Esto da lugar al establecimiento de un modelo de poder que genera nuevas identidades jerarquizadas en relaciones de dominio -en lo económico, lo social, lo cultural, y lo político- de las identidades "europeas", sobre las "no europeas", que si bien es originado en América, posteriormente se extiende a lo largo de todo el mundo colonizado, en el escenario del capitalismo eurocéntrico y colonial (Quijano, 1999, pp. 101-104).

En este marco de racialización inferiorizante en el que el habla de las lenguas aborígenes en América es prohibida, ${ }^{2}$ sus símbolos y expresiones sensibles son proscritos, y sus formas de conocimiento demonizadas (Castro-Gómez, 2005, p. 60), se da la instalación del mundo colonizado, con una geopolítica del conocimiento de corte eurocéntrico que presenta el conocimiento como un asunto deslocalizado y descorporalizado, y que sitúa a la modernidad europea como patrón universal poseedor de una epistemología superior destinada a ser incorporada por todas las regiones y poblaciones del planeta; desde allí se concibe la idea

2 El Rey Carlos III, desde la última parte del siglo XVIII, prohibió el uso de las lenguas indias en las colonias americanas so pretexto de unificar lingüísticamente el imperio con el fin de facilitar el comercio, desterrar la ignorancia e incorporar a sus vasallos a un solo modo de producción (Castro-Gómez, 2005, p. 12). 
de América Latina como región del mundo compuesta por poblaciones carentes de la razón moderna, peculiaridad que marcará las posturas de sus estadistas e intelectuales en pro de asumir el reto de la modernización del continente, puesto que desde allí se asume a la modernidad como destino histórico de los humanos y no como la justificación de la colonialidad del poder (Mignolo, 2002, pp. 18-19).

De este modo, la relación modernidad/colonialidad se inscribe en un estatuto de conocimiento hegemónico que hace parte de un sistema-mundo soportado por una división internacional del trabajo y por la generación de epistemologías que reproducen los patrones del pensamiento colonial, que a su vez consagra las jerarquizaciones e inferiorizaciones eurocentradas desde lo cultural y lo racial, determinando las subjetividades imperiales y colonizadas mediante relaciones de exclusión y subalternización (Maldonado-Torres, 2007, pp. 129-130). Y es desde allí que tiene lugar la colonialidad del ser que cubre la experiencia vivida de la colonización en sus dimensiones de la vida social, el lenguaje, el conocimiento, la subjetividad, el género y la sexualidad (Mignolo, s.f.).

En asocio con su entroncamiento en el poder, el saber y el ser, la colonialidad se asienta en el dominio del eurocentrismo respecto a las cosmogonías de los sujetos colonizados (Walsh, 2010). Esta situación, que en caso de América implica la invalidación de las articulaciones espirituales del humano respecto a la naturaleza, en las comunidades indígenas y las de la diáspora africana en este continente apunta a extirpar sus cosmovisiones, filosofías, religiosidades y principios civilizatorios destruyendo sus colectividades y prácticas de existencia (Walsh, 2010, pp. 90-91).

Teniendo en cuenta la imposición universal eurocéntrica en términos de sus concepciones del ser, correspondiente al sujeto moderno, del conocimiento y de la organización social, así como de los modos que esta considera lícitos en términos de las formas de vida y de relación entre los seres humanos y entre ellos y la naturaleza, es posible referirnos a una colonialidad en lo sensible, que opera mediante las concepciones estéticas occidentales, ${ }^{3}$ instalándose como dispositivo de control y exclusión de la "sensibilidad de mundo" de los pueblos no europeos, es decir de las experiencias de

3 "A partir del siglo XVII, el concepto aesthesis se restringe, y de ahí en adelante pasará a significar 'sensación de lo bello'. Nace así la estética como teoría, y el concepto de arte como práctica." (Mignolo, 2010, p. 13) conocimiento sensible no eurocentradas, de sus modos de vida y de relación sensorial respecto a la naturaleza, para la supresión de la articulación de pensamiento/ sensibilidad/acción en los cuerpos, las dimensiones sensoriales, las memorias, los afectos, las lenguas y las epistemes colonizadas (Mignolo, 2011).

Dentro del necesario cuestionamiento a la hegemonía del sistema-mundo moderno/colonial, la descolonización de lo sensible se perfila como un territorio en el que se confrontan, por una parte, el posicionamiento privilegiado de la estética occidental como teoría de lo sensible; y por otra el estatuto, como sujetos de diálogo, de las múltiples sensibilidades generadas por las exterioridades que han sido producidas o afectadas como resultado de la relación colonial.

En este escenario de tensión frente a la imposición, invisibilización o reconocimiento de los sensibles, las poblaciones colonizadas que han sido sometidas históricamente a relaciones de dominio y subalternización por el sistema-mundo moderno, evidencian sus propias sensibilidades "otras" a través de experiencias particulares de re-existencia ${ }^{4}$. Entre ellas se cuentan los pueblos indígenas latinoamericanos: el pueblo uitoto, ${ }^{5}$

$4 \quad$ Adolfo Albán entiende por re-existencia a los dispositivos creados por las comunidades para confrontar y descentrar la realidad y las lógicas de la inferiorización, el silenciamiento y la visibilización negativa de las comunidades y culturas colonizadas, entre ellas los afrodescendientes e indígenas, que han sido instauradas por el proyecto hegemónico desde la colonia hasta nuestros días. La re-existencia permite inventar cotidianamente la vida, y apunta a la búsqueda, en las profundidades de las culturas, de formas organizativas de producción, alimentarias, rituales y estéticas que permitan dignificar la vida y re-inventarla para permanecer transformándose (Albán, 2009, p. 94).

5 El pueblo uitoto, ha tenido contacto con los europeos desde la segunda mitad del siglo XVI, siendo objeto de intentos de implantación del sistema de encomiendas, de misiones de evangelización, y de "guerras justas" dirigidas al "rescate" e intercambio de personas indígenas "por mercancías y hachas" para su esclavización (Pineda Camacho, 2000, pp. 23-26). Entre los siglos XIX y XX, ha resistido prácticas de "conquista" para su incorporación subordinada a la economía comercial en la extracción de quina, maderas, pieles, animales tropicales, coca, y actualmente mediante la extracción de oro, en actividades controladas por mafias y grupos irregulares, partícipes del conflicto armado en Colombia (Vargas Tovar, 2012). Desde inicios del siglo XX y hasta su tercera década fue víctima de la "cauchería", etnocidio comercial realizado por aventureros y empresarios peruanos y colombianos, con apoyo de capital inglés, centralizados por la Casa Arana, que produjo la esclavización y asesinato de decenas de miles de personas indígenas amazónicas colombianas, bajo la creencia de que estas no eran gente, sino animales (Pineda Camacho, 2000, pp. 71-201). En virtud de la Constitución de 1886, con secuelas que se viven hasta la actualidad, posterior a 
, el mico nocturno, y Mayári Jitoma, el pájaro carpintero, domina en secreto a las gentes y mira al niño-Jitoma como su siguiente víctima. ${ }^{12}$

Con el tiempo, Jitoma, al que se le ha ocultado la existencia y muerte de su padre, y quien siente atracción innata por los trabajos de la caza —en su juego infantil inventa pequeñas bodoqueras para perseguir insectos y pequeños animales - se encuentra con Quechátoma, su perspicaz hermano. Quechátoma es el Sol nocturno: es Luna, es otro Sol, cuya existencia el mismo Jitoma desconocía. Él es la esencia —-"la mantequita” de su padre- que en el momento de su muerte voló, se escondió bajo una rama y posteriormente se convirtió en el huevo del colibrí. ${ }^{13}$

A partir de este encuentro, una vez que Quechátoma pasa de ser el huevito del colibrí, para transformarse en un niño "materializado", la relación entre los dos hermanos - que se centra de modo particular en las actividades de la caza y de la pesca, mediadas por la permanente alusión y pregunta respecto a la existencia del padre y a la herencia que éste les ha dejado- ${ }^{14}$ se orienta a la realización de "un estudio" conducente a develar la identidad del padre, la autoría, motivaciones y circunstancias de su muerte, y la búsqueda de la manera de superar el estado de sometimiento de los dos soles, por el poder antropófago de Gaimoł Riama, quien además se apropia, sin que ellos lo sepan, del producto de su trabajo. ${ }^{15}$

En la realización de tal propósito, Jitoma y Quechátoma van encontrando los rastros y el territorio de su padre: la huella de su pie, los árboles que él ha tumbado para la siembra y los frutales que ha cultivado. Así,

12 Gaimoł Riama, como el poder en el dominio y Jitoma como
la "humanización" del modo de existencia del humano, configuran
una relación de tensión entre los intereses individuales y comunita-
rios en la existencia humana, el alejamiento y el acercamiento entre
las gentes, el ocultamiento y la visibilización de las memorias, el no
respeto y el reconocimiento respetuoso de las diferencias (Román,
2009 ).
$13 \quad$ En idioma uitoto-minica, Fizido es colibrí. Quechátoma es el
espíritu del papá que quería salvar al pequeño Jitoma de ser devorado
por Gaimoł y a quien Jitoma va a conocer como su hermano.
$14 \quad$ A los dos huérfanos se les afirma que ellos no tienen padre,
frente a lo que Quechátoma señala la imposibilidad de no tener un
padre y pregunta por el Obiyakat (bodoquera), la Garađa (Palo de
trueno), y el Abini (Peto) que su padre les ha dejado (Román, 2013).
$15 \quad$ Todo el trabajo de caza y pesca realizado por Jitoma y su
hermano terminaba siendo entregado al tigre caníbal por la madre
(Ibid.).

penetrando en la selva, en dirección al oriente, ${ }^{16}$ contraviniendo la prohibición de la madre — puesto que allí se encuentra el escondite de Gaimoł Riama-, los hermanos van cazando, interrogando, curando y liberando a todos y cada uno de los animales-gente que están sujetos al poder del tigre caníbal, hasta que "Un día flecharon a la lagartija y por fin fue la Lagartija Roja la que habló. La lagartija dijo:

“Sobrinos no me flechen; yo les voy a decir cómo murió su papá. Yo duermo adentro de la bodoquera de su papá." [...] Cuando ellos la flechaban, la lagartija Roja se escondía dentro de la bodoquera del papá, que estaba oculta entre los tejidos de puy del techo de la maloca. Así fue como ellos encontraron la bodoquera (Sánchez, 1990).

Este encuentro y conversación con la lagartija roja será fundamental para que los dos soles generen la estrategia mediante la cual darán caza a Gaimoł Riama, terminando con su dominio violento sobre el mundo: lo flecharán con la bodoquera del padre, usando dardos untados con el "veneno" que la madre guarda en su vagina. ${ }^{17}$

\section{Tres conceptos-prácticas vitales}

Soportados en el cuento de Jitoma, de modo específico en la idea del "estudio" que él y su hermano Quechátoma desarrollan en la búsqueda de su padre y de su herencia, nos referiremos a tres conceptos-prácticas vitales del pensamiento uitoto que comparten como base común la enunciación del necesario equilibrio de las fuerzas vitales padre-madre como condición de mantenimiento de la vida en el tejido mundo; son estos: 1) Medir la mano, que implica el equilibrio de las fuerzas vitales para la apropiación, precisa y responsable de la acción vital humana, respecto a la fertilidad del mundo; 2) Fortalecer el manejo de los aires de aliento, el equilibrio de las fuerzas vitales que hacen posible el conocimiento y la sensibilidad humana mediante su articulación armónica con el tejido-mundo; y 3) Encontrar el propio cuerpo, el equilibrio de las fuerzas vitales en la configuración de la persona-cuerpo, respecto al

\footnotetext{
16 La dirección oriente refiere al mundo de abajo, de donde todo viene al "mundo creado": "el viento, la luz, la lluvia fértil, el verano, etc. todo sube desde el mundo de los padres". (De Corredor, 1986, p. 344) 17 "Así el tigre se bajó. Ya iba bajando la mitad de la escalera, cuando Jitoma le manda un dardo en medio de las costillas. Entonces el tigre se devolvió. Pero Jitoma le pegó los tres dardos más untados. entonces el tigre se cayó muerto. El mundo tembló por segunda vez [...] y se oscureció; todos los animales, los pájaros gritaban. Se murió el amo de ellos." (Román, 2009).
} 
conjunto del tejido-mundo, lo que se concreta mediante el alimento-conocimiento.

Para este propósito, es necesario señalar brevemente algunos aspectos particulares del relato, así:

En primer lugar, Jitoma es presentado como un Jaiguéniki o huérfano, hombre-sol que ha sido despojado de su herencia de conocimiento para vivir como humano ${ }^{18}$ por su pasión por el poder en el dominio encarnado por Gaimot Rtama. Tal despojo, que ha tenido lugar en la ruptura de los tejidos que vinculan a Jitoma individual y colectivamente como "gente", se efectúa en el ocultamiento de la existencia y la identidad de su padre, parte fundamental de su tejido raíz; en el encubrimiento de la motivación, las circunstancias y la autoría de su muerte; en el sometimiento de su madre al asesino del padre; en la negación del legado que le corresponde en términos territoriales y de conocimiento; en la apropiación soterrada del producto de su trabajo; y en su disposición como la siguiente víctima al canibalismo de Gaimoł Rtama.

En segundo lugar, Jitoma, atendiendo al sentido amplio de la definición de Jaiguénikł —inicialmente por sí mismo y posteriormente mediante el diálogo con su hermano Quechátoma y con las demás gentes que han sido esclavizadas por Gaimoł Riama- despliega su capacidad de resistencia al despojo buscando el respeto, enraiza en su identificación con sus progenitores, teje historias con otros, se reconoce como sujeto de conocimiento y de transformación, y se potencia como agente modificador de las relaciones de sometimiento al poder en el dominio que le han sido impuestas a él y al mundo por Gaimoł Riama. ${ }^{19}$

\footnotetext{
18 "Saber vivir como humano" es generar un modo de vida "humano" en la relación con el "mundo creado", fundamentado en el respeto de la ley de origen y su palabra de vida, lo que implica: saber trabajar solo y en comunidad; tener cultura, tradición y lenguaje; no distanciarse de la condición humana comunitaria que está basada en el respeto respecto a las demás gentes y pueblos y su forma de vivir y trabajar; y cumplir con la responsabilidad humana de respetar y cuidar la naturaleza (Román, 2010).

19 El sentido de la palabra Jaiguéniki-huérfano se extiende a los siguientes: Jaigue/dolor, aguantar, resistir; ánimo en sí mismo/buscar el respeto; Niru, huérfano; Níjidé, como una hierba que pega y enraiza; Niya: tejer, dejar muchas historias, mucho tejido de la palabra; Ru-Iru, vasija, matriz, fuerza, capullo de un gusano, mariposa, que se enfoca en la capacidad del huérfano como entidad contenedora de fuerza de conocimiento destinado a ser materializado. Imérufidé, capullo de Mojojoy, poder de metamorfosis del huérfano; Obiaru: (Carcaj, aljaba) donde se cargan las flechas. (Román, 2013c)
}

Es pertinente observar que tal potenciación de la capacidad transformadora de Jitoma, que pone punto final al estatuto del poder en el dominio, establecido por Gaimoł Rtama, es el producto del "estudio" realizado por él en compañía de su hermano Quechátoma. Este estudio, cuyo propósito es el restablecimiento de su vínculo individual y colectivo como "gentes" —-mediante la liberación de su madre, la re-apropiación del legado territorial, epistémico y vital paterno, y la recuperación del producto de su trabajo-, implica la proyección del poder de equilibrio entre las fuerzas padre y madre que se deriva del conocimiento de los huérfanos, ${ }^{20}$ teniendo lugar esto último en el uso de la bodoquera del padre para disparar las flechas impregnadas con el veneno que la madre guarda en su vagina, único modo con el que Jitoma y Quechátoma pueden dar caza a Gaimoł Riama (Román, 2009).

Se trata, en suma, de "un estudio" dirigido al restablecimiento de las condiciones necesarias para "vivir como humano" —que han sido vulneradas por el poder en el dominio- para lo cual se requiere el equilibrio de las fuerzas padre-madre, en articulación armónica de los intereses individuales y colectivos, en el contexto vital de la comunidad del tejido-mundo, lo cual remite a varios mecanismos del conocer, propios del pensamiento-sensible uitoto, entre los que mencionaremos:

\section{Medir/Ensayar la mano: \\ "Onoi Faka: Mano, medir. Onoi: Sensibilidad, emo- ciones, equilibrio". (Roman, 2010b) Y el niñito iba creciendo y se iba inventando qué hacer, ese Jitoma se inventaba cerbatanas chiqui- tas con tallitos de maticas para cazar mosquitos que se paraban en la espalda de la mamá y en cualquier otra parte. (...) Ya más grande andaba con flechitas, que él fabricó, hechas con una hierba amarga. Él inventaba trampitas para coger animalitos pequeños y jugando, él iba conociendo el monte cada vez más lejos de la maloca. (Sán- chez, 1990)}

Onoi Faka: Medir la mano es el ejercicio inicial para la realización de toda nueva actividad que es asumida en el propósito de "enfrentar la vida", para lo cual se parte del reconocimiento y la potenciación de las cualidades específicas propias de cada humano, que son las que le permiten configurar su interacción armónica con las fuerzas vitales, posibilitando su existencia y la de su

20 Inscrito en la herencia paterna: la bodoquera -Obiyakai-, la Garađa (P alo de trueno) y el Abini (Peto) del padre. 
comunidad. Así, encontramos que a cada persona "le nacen" condiciones y modos particulares para el desarrollo de las acciones que le procuran la vida, ${ }^{21}$ y que la persona debe lograr cabal conocimiento de estas, para su manejo preciso y responsable. Entonces, es tarea de cada quien la búsqueda y el desarrollo sistemático de los modos más idóneos para la realización de "sus trabajos", ${ }^{22}$ aun partiendo de la identificación de sus propias limitaciones. Hallamos, así, gente con "mano muy caliente o muy pesada" para efectuar determinadas actividades, como en el caso de la siembra de una planta en particular, "o aún en el manejo de las máquinas" (Román, 2010b). Tales especificidades conducen a la "preparación" o "curación" de la mano de la persona, para equilibrar o potenciar sus características sensibles (como cuando, por ejemplo, se le aplican picaduras de avispa para desarrollar su poder de fertilización), o a la determinación de las dietas necesarias para proteger las facultades del cuerpo -ya que este es considerado como algo "delicado", objeto de sensibilidad y de posible afectación - o la abstención de exponer la mano al fuego (Román, 2012b).

Puesto que Faka es medir en metros, probar algo en la boca, probar algo en el peso; que Fakariyá es practicar, entrenarse; y que Onoi indica el equilibrio en la sensibilidad y en las emociones, medir la mano compromete la condición de sensibilidad, entendida como la identificación y cuantificación de aquello específico con lo que el humano interactúa. El desarrollo de las habilidades -en tipo, modo e intensidad- para la realización de las acciones requeridas para tal propósito; y el manejo equilibrado de las emociones que se derivan de toda relación entre humanos, y entre ellos y los demás seres, para el mantenimiento de la vida (Ibid).

Otras palabras del idioma Uitoto que precisan el sentido de medir la mano son:

Ede, que es llorar, remite a la lectura de las señales de la interacción sensible, en una dirección similar a la de la comprensión del sentido del llanto de un niño. Se entiende que una "criatura no puede hablar, ya que el

\footnotetext{
21 En esto inciden sus características corporales, sus preferencias y su ancestralidad.

22 Por ejemplo, mediante la experimentación en los materiales, los procedimientos de elaboración y las proporciones de los instrumentos de trabajo -en concordancia con las características corporales y habilidades del hacedor-como lo es la bodoquera en el caso de la caza; o en el ensayo metódico de los modos de cultivar una planta, para lograr que esta se desarrolle y fructifique de la mejor manera, en arreglo a las particularidades de la mano de quien la siembra.
}

llanto de la criatura no habla, pero que su llanto "avisa" qué es lo que el niño siente" (Ibid).

Yua, es avisar dando una señal, puesto que "todas las cosas naturales o creadas por el humano, hablan, son señales, hablan en silencio; son susurros, palabras"; ${ }^{\prime 23}$ Yua advierte la importancia de atender a las señales que se perciben por la visión, por el sonido, por el olor, por la temperatura, por la pisada o por cualquier otro medio, acerca de las situaciones y movimientos de la naturaleza, o de los efectos de las relaciones entre las gentes, en donde se generan eventos que pueden afectar al humano. ${ }^{24}$ Yua también remite al saber dejar señales, es decir, al realizar acciones precisas y responsables, como el buen cazador, que mata con una sola flecha (Ibid.).

Fiaikaná señala la precaución, el ritmo adecuado, la fuerza, la delicadeza, el requerimiento de andar despacio y con cuidado para reconocer las reglas de la interacción sensible, y así actuar con precisión y "no cometer disparates" (Ibid.).

Eéruya es tratar con delicadeza, cuidar mucho algo que se aprecia "porque" hay situaciones y cosas que son afectadas por la acción humana y ante lo cual "ellas no se pueden cuidar por sí mismas" (Ibid.); así su belleza y duración son afectadas por el humano. Eéruya, siendo el cuidado de todo lo que rodea al humano, conduce al respaldo y cuidado de sí y de los otros, dado que "nuestras acciones tarde o temprano terminan por afectarnos" (Ibid.).

Rairuíredé, es aprender a medir el pensamiento, la palabra y la acción, investigando, reconociendo que las interacciones en los humanos y en la naturaleza implican cadenas de afectaciones; Rairuíredé también comporta el respeto frente a lo que la gente hace y tiene, porque ello ha implicado un esfuerzo, la realización de un trabajo (Ibid.).

Énoga, es guardar bien, asegurar, proteger las gentes y las cosas; implica también la precaución en la realización

23 "Si usted no lo quiso entender, también hay causas. Si ya lo avisó, por medio de señales, de otras formas ¿qué más quería?" (Ibid).

24 El humano se ve "afectado" en su interacción, desde e desconocimiento de "lo sensible". En ese sentido, el resultado de la afectación es el desequilibrio: el dar vida en uno, al problema del otro. Este tipo de situaciones, son en sí mismas "como pruebas para ver qué tan firmes estamos". Para mantener el equilibrio en lo sensible, es necesario proyectar la interacción en el horizonte de lo comunitario, donde las cosas cobran sentido. (Román, 2012b) 
de las actividades, guardar fuerzas para poder mover algo. Hay momentos en que es necesario "trabajar más suave", guardando fuerzas para más adelante (Ibid.).

\section{Fortalecer el manejo de los Aires de Aliento}

Y en una de esas salidas, él va por ahí caminando y de pronto ve algo: el huevo del colibrí (Fizido), la mantequita del papá que se había convertido en un huevito como de colibrí; él lo llevó hasta la maloca y lo puso en un totumito con algodón, bien tapadito para que huevito reviente. Él mira cada nada y el huevito no quiere reventar; le mira dos manchitas al huevo, que son sus ojos, y Jitoma chuzó una de las manchitas y lo dejó tuerto. [...] Otro día, tan pronto el salió de la maloca, el huevo ya se estaba madurando y ya hablaba; cuando Jitoma y la mamá salen a la chagra, el huevo ya hace bulla. Y Jitoma dijo: ¿Pero quién, pero quién habla en la casa, quién canta, así? (Sánchez, 2019)

Comini Yiike. Comini, es hierba humanizadora; Yiike es hierba, esencia, que encierra todas las demás esencias - del padre y de la madre-y que forma "la parte humana de la gente". Es compartida por la "gente de barro" y por la "gente viva". ${ }^{25}$ En su definición como hierba humanizadora, el Comini Yiike es el conjunto de fuerzas específicas que dan al humano vida, conocimiento y sensibilidad. Cada una de estas esencias organiza y orienta el modo de vivir en aspectos particulares de lo personal y lo comunitario en su articulación con el conjunto de la vida del tejido-mundo; así, las esencias que se asocian con la fuerza padre, señalan y constituyen modos específicos del vivir-conocer, mientras que las que se articulan en la fuerza madre apuntan de modo especial al vivir-sostener y orientar e conocimiento en la responsabilidad humana respecto a su siembra, mantenimiento y efectos de su uso. Siendo el humano animado en su cuerpo y en lo espiritual por estos aires de aliento, debe fortalecer el manejo de estas fuerzas, de forma tal que cuando alguna de ellas "escasea", como en el caso de una enfermedad, se hace necesaria su búsqueda y equilibrio en la hierba que contiene su esencia (Román, 2010a).

\section{Esencias de la Fuerza del Padre}

En lo referente a la fuerza padre, el Comini Yiike contiene cuatro esencias, en aire de aliento, que

\footnotetext{
25 La "gente de barro" corresponde a la continuidad de colores-esencias que fue mezclada por el Padre Creador para dar lugar ala "gente viva", siendo sus ancestros.
}

pertenecen a las gentes de barro y que corresponden a cuatro distintos canales del conocer, cuales son el Aire de Aliento que nace de uno mismo; de premonición, corazonada; del recordar, de la memoria; y que mantiene, que sostiene la sabiduría del conocimiento:

Yonera Yagiiyi: Aire de Aliento que nace de uno mismo, que habla, que enseña, que guía a toda persona, aun cuando la persona esté sola. Todo niño y persona posee una fuerza que habla para que él se mueva y descubra; en ocasiones hay que buscar este aire en el silencio, en la soledad, "en medio del monte" (Ibid).

Fidira Yagiiyi: Aire de Aliento, de premonición, corazonada: se siente lo que sucede en el presente aun cuando esto no haya sido visto; se siente lo que va a suceder, aun cuando ello no haya sido informado; por este aire todo puede ser visto; se puede tener certeza respecto a un asunto, sin conocer la causa. (Ibid). Uibira Yagiiyi: Aire de Aliento, del recordar, de la memoria, el humano siempre está recordando (Ibid).

Nimaira Yagiiyi: es Aire de Aliento que mantiene, que sostiene la sabiduría del conocimiento, para que este no se borre. Los niños olvidan mientras están jugando, pero el humano entre más anciano "es" más conocimiento; un anciano no olvida el conocimiento. Este último aire de Aliento, que por parte de la fuerza del padre es Nimairada, es compartido por la fuerza madre, por la gente viva, con la palabra Nimaira Imugu. (Ibid)

\section{Esencias de la fuerza de la Madre}

En lo que compete a la fuerza madre, el Comini Yiike contiene, los Aires de Aliento de endulzamiento, que siendo "la parte humana de la gente" —o las esencias que corresponden a las gentes vivas - equilibran al humano, dando sentido, dirección y responsabilidad a su existencia, conocimiento y sensibilidad, respecto al mantenimiento de la vida del tejido-mundo. De esta manera, tales esencias permiten al humano vivir y conocer mediante -entre otras relaciones de valoración del efecto de sus acciones-, el respeto por la vida, el vivir en el corazón y el pensamiento dulce, la regulación responsable de las emociones, el escuchar y discernir en el conocimiento; el experimentar e investigar; el sostenimiento de las personas y la comunidad; y el ejercicio de la creación, así:

Fareka Yagiiyi: ("La yuca Fareka es más agua que masa de yuca. Eso nos hace crecer") (Ibid). Esencia de yuca dulce, es la capacidad humana de "sentir el sentir de la naturaleza"; es aire de aliento para que la persona crezca responsablemente con el pensamiento y con 
el corazón-dulce, en el cuerpo, físicamente, con "la sangre que es el agua que tenemos, para que no se nos escasee" (Ibid). En esta esencia, el humano valora con respeto y reconoce lo irremplazables que son el agua y los alimentos, para la vida (Ibid).

Jaibikie Yagiiyi: Esencia de albahaca: este es un aire de aliento que puede cortar lo negativo producido por las carencias en el conocimiento-sensible —es decir, los errores producidos por el desconocimiento del existir humano en el respeto a la naturaleza y a la comunidad del tejido-mundo- para que crezca lo positivo (Ibid). Nocekue Yagiiyi: Esencia que equilibra entre el calor y el frío; "ni calor, ni frio". Todo es conocimiento. Esta esencia es luz que ilumina y orienta para discernir y recibir "un buen conocimiento" (Ibid).

Chapenui Yagiiyi: Esencia equilibradora de todo el cuerpo y del sistema nervioso; regula el fuego que está en cada persona, fortaleciendo su responsabilidad, para no enfurecerse (Ibid).

Tiraka Jagiiyi: Esencia de tiempo de vida, de tiempo de morir; ayuda a entender la vida en la realización de sus propósitos, de su sentido y de su disfrute, y a partir de ello, a aceptar la muerte (Ibid).

Dirima Yagiiyi: Esencia que regula el organismo y que sostiene el cuerpo en las dietas -prácticas de ayuno, abstinencias físicas y espirituales- para no cometer errores en la obtención de un propósito, como, por ejemplo, cuando se suspende la comida, la bebida, la práctica de la relación sexual o las actividades para la resolución de los problemas (Ibid).

Naimekie Yagiiyi: Esencia de dulzura, de corazón y pensamiento dulce, manso, tranquilo, de afecto, de cariño, de amor, de paz y de felicidad; esencia de trabajo con alegría (Ibid).

Mozira Jagiiyi: Es aire con el que el padre creador se sostuvo para no caer en el vacío y con el que sostuvo las cosas para que estas no desaparecieran; es presencia del padre creador en el humano, como conocimiento y sabiduría que quedan en su "corazón y cerebro", ${ }^{26}$ para que sean recibidos, mantenidos, no olvidados (Ibid). Es aire-pensamiento-palabra para no desviar, para sostener el conocimiento en cada miembro de la comunidad, para mantener a la comunidad en el acuerdo-conocimiento-alimento de lo que la comunidad habla. Es aire de detener a los demás "para que no caigan"; para detener las enfermedades (Ibid). Yiira Jagiiyi: Es aire de aprender a escuchar-sentir la voz del silencio, de la algarabía, del ruido, de la vida, de la muerte; de la alegría, de la tristeza, de la enfermedad, del bien, del mal. Conlleva discernir qué se recibe y qué no, así como el saber qué hacer con aquello que se escucha (Ibid).

Finora Jagiiyi: Aire de Aliento de crear, de hacer, de arreglar, de transformar (Ibid).

Yiara Jagiiyi: aire de aclarar las cosas, de ver, de diferenciar, de identificar las cosas y su textura, con miras a "pasar", a actuar con pertinencia y precisión. Cada cosa que se va aclarando, que se alcanza a ver, es Yiara (Ibid).

Ainira Jagiiyi: Es aire del origen, de seleccionar, de clasificar, de ordenar, de experimentar, de investigar, para vivir. Es aire de saber qué puede ser mezclado con qué y con qué no; de reconocer qué cosas pueden ser "tocadas" y cuáles no. A este aire, "el blanco no lo ha podido coger en equilibrio, él piensa que lo descubrió. Hay cosas que hay que dejarlas quietas, para la vida. Son vida, dejándolas quietas" (Ibid).

\section{Encontrar el símbolo de nuestro cuerpo ${ }^{27}$}

Y ahora Jitoma hablaba y andaba con su hermano por entre el monte cazando pajaritos e insectos. $Y$ ellos ya estudiaban; veían a los papás de los pajaritos y se preguntaban porque ellos no tenían papá y mamá. Y ellos preguntaban a la mamá que porqué ellos no tenían papá. (Sánchez, 1990)

Se entiende que todo lo existente es sembrado — sea piedra, animal, o planta- y que el humano siendo semilla y planta requiere del alimento de las fuerzas vitales, padre-madre, para su crecimiento, mantenimiento y convivencia con las gentes de sus comunidades próximas y con las del tejido-mundo en su conjunto. Esto conduce al "encuentro del propio cuerpo", es decir, al trabajo de la persona en el conocimiento-sensible para

piense con el corazón; es decir, guardando el conocimiento en el afecto - que es un pensamiento constante, sin olvido- "para estar seguros de lo que se piensa, se dice y se hace." (Román, 2013a) 27 (Román, 2013b) 


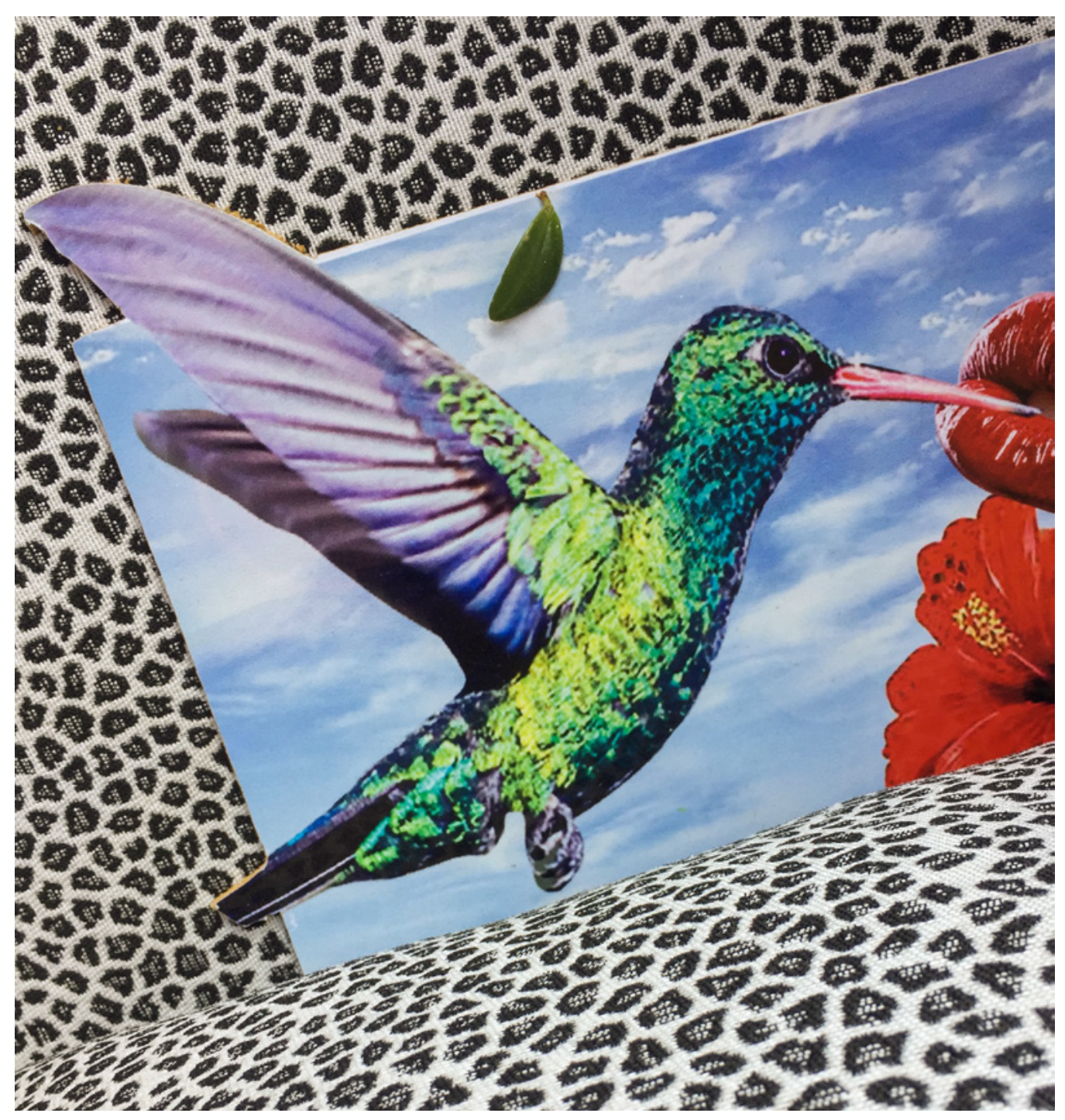

Jaguar y Colibrí, del almanaque 2020 "El Chupaflor, del Barqueadero, Barranquilla" (2020). Fotografía: Andrés Corredor.

el mantenimiento de su propio equilibrio personal-corporal como producto de la relación de las fuerzas vitales.

Asumiendo la educación como actividad de conocimiento-alimento del humano, el encuentro del propio cuerpo conlleva el sembrar conocimiento en quien aprende, procurando que las palabras sembradas den su fruto, en forma de salud, inteligencia, y sabiduría. ${ }^{28}$ La siembra del conocimiento requiere ser realizada con amor, con historia y con disciplina, partiendo de la identificación de la sensibilidad fundamental que articula las fuerzas padre y madre en las relaciones existentes entre las comunidades de las plantas y la de los humanos. Esto se concreta en el cultivo y consumo de los alimentos, atendiendo a pautas conducentes al

28 Rigaire: Es lo sembrado. Riya / Riga: Es lo que se siembra. Rigámuiré: Ya está materializado. Son todos los seres existentes. (Román, 2012a) equilibrio interno del humano y al de este respecto al tejido-mundo (Román, 2011); entre ellas encontramos:

- El respeto de los ciclos de la vida y de los alimentos, para evitar las enfermedades (Román, 2012).

- El mantenimiento de la variedad de la vida: dado que la existencia del bosque depende de la variedad de sus plantas, la siembra humana es realizada en policultivo. ${ }^{29}$ Esta forma de siembra recibe el nombre de "cultivo humanizador", puesto que reconoce y asume de modo responsable el poder de la intervención humana en el mantenimiento o declive de la variedad de la vida (Ibid).

- El mantenimiento de la continuidad de la vida: en consideración que para sembrar hay que tumbar el conjunto de plantas que ha sido tejido por la

29 También se reconocen siembras realizadas por los animales, el viento, el agua. 
naturaleza previamente a la intervención humana, se siembran plantas "parientes" de las que se tumbaron, para "guardar" el polen de la vida que se deforestó, y de ese modo permitir el regreso de las plantas silvestres. ${ }^{30}$

- El fortalecimiento de la vida humana en comunidad: en correspondencia con el comportamiento de las plantas, el policultivo enseña al humano a vivir en comunidad: las plantas conviven en la diferencia dentro de un mismo territorio, sin discriminarse unas a otras, proporcionándose protección mutua frente a "las plagas" (Román, 2012a).

- La atención a las necesidades del cuerpo humano en correspondencia a las fuerzas específicas provistas por las diferentes plantas: Las cualidades específicas de las distintas plantas con relación a las fuerzas vitales, se concretan, por ejemplo, en su lugar de fructificación respecto a la tierra - algunas lo hacen en su interior, otras crecen en su superficie a distancias cortas del suelo y otras lo hacen a gran altura-, correspondiendo en cada caso a diferentes círculos energéticos (Román, 2012).

- La humanización del sembrado para la alimentación y curación del humano: todo lo que hace parte del cuerpo del humano, al igual que lo que le molesta o enferma, debe ser sembrado en la chagra; así, se siembra teniendo en cuenta: la sensibilidad de algunas plantas respecto a "la parte masculina o femenina del humano"; 31 la correspondencia de los alimentos con relación a las diferentes partes del cuerpo; ${ }^{32}$ y la transformación de las enfermedades en alimentos. ${ }^{33}$

Buscar el propio cuerpo es "humanizarse y volverse gente", mediante el equilibrio de las fuerzas vitales padre-madre en el cuerpo de quien siembra

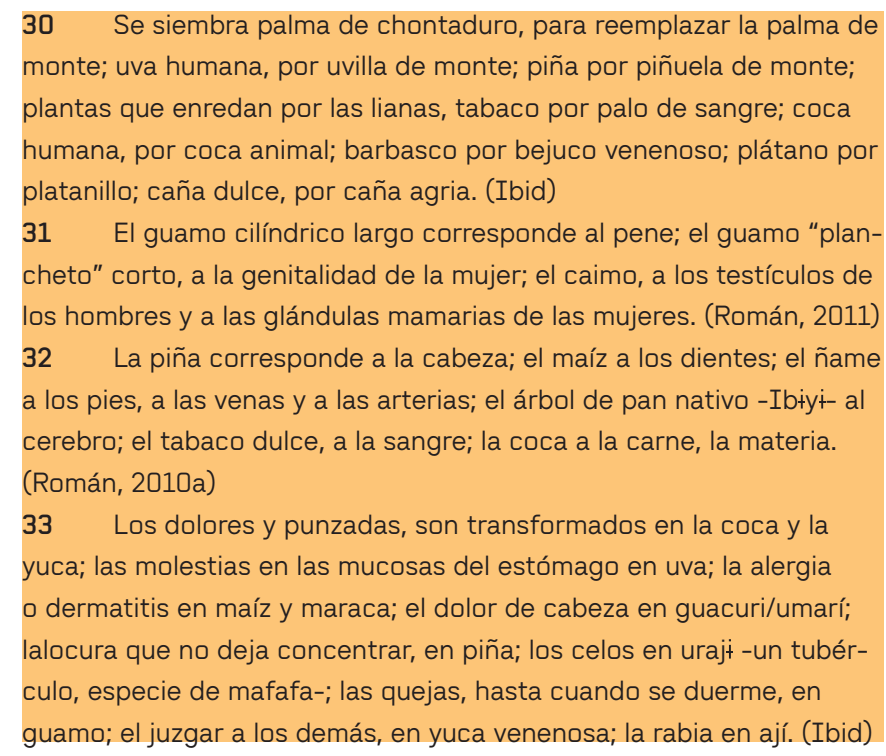

conocimiento. Se siembra conocimiento del mismo modo como vamos configurando la existencia. El humano se alimenta recordando y poniendo en vivencia lo que recuerda. Al igual que las plantas, se alimenta "chupando" el ambiente, el aire, la energía en que vive y de la que se rodea; las plantas son parte constitutiva de ese ambiente (Román, 2010b). Cada humano siembra y se alimenta de los frutos de su trabajo, encontrando en sí, en su comunidad y en su conexión en el tejido-mundo, el símbolo del cuerpo del padre y el símbolo del cuerpo de la madre (Román, 2013b), es decir, el símbolo de su propio cuerpo.

\section{En el diálogo intercultural, hacia la descolonización en lo sensible}

Jitoma va a tener un hermano - como un reemplazo de Jitoma - reemplazo, así es, va a ser. Acaso no tener padre, tiempo, cosas, yo ¿No voy a tener padre? ¿Acaso hay cosas o tiempo que prohíben tener padre, y por esa razón yo no voy a tener padre? El papá de Jitoma como herencia, Garađa está; el papá de Jitoma como heren-

cia, Obiyakaidi está. ¿Acaso no tener padre; tiempo,

cosas, yo? ¿No voy a tener padre? El papá de Jitoma como herencia, Abini está. ¿Acaso no tener padre? ¿No voy a tener padre ${ }^{34}$

Las resistencias de los sistemas de pensamiento de los pueblos no coloniales/no occidentales, a la descalificación que les ha sido impuesta históricamente por el eurocentrismo, configuran territorios epistémicos que sostienen diferencialidades autónomas respecto a la lógica de la exclusión de la colonialidad —del poder, del saber, del ser, y del sentir-, en las que se evidencian posiciones "otras" respecto a los modos de asumir, relacionar y valorar las nociones de conocimiento y sensibilidad, los intereses y modos del conocer y del sentir, y las formas de relación entre quienes convergen en tales procesos.

Estas maneras de asumir lo sensible por parte de los exteriorizados por la hegemonía del sistema-mundo moderno/colonial, que se configuran como formas no eurocéntricas de articular la existencia humana -en sus aspectos vitales, corporales, sensoriales, afectivos, cosmogónicos, sociales y políticos- mediante éticas fundamentadas en el respeto para con la naturaleza y la vida, y en el reconocimiento mutuo entre las gentes y la existencia en comunidad, les permite posicionarse como interlocutores estratégicos no jerarquizados entre sí, desde conceptos-prácticas de existencia que 
cuestionan el dominio eurocéntrico y configuran modos "otros" de lo sensible, para su descolonización.

En esta intención, se señala el conocimiento-sensible del pensamiento uitoto, que en su concepto del "saber enfrentar la vida", asume la existencia humana desde el equilibrio entre las fuerzas padre-madre, para el mantenimiento de la relación armónica entre las gentes "humanas" y las "no humanas", entendiendo el conocimiento como el comprender el funcionamiento del mundo para la generación de modos de existencia en armonía con el "sentir de la naturaleza" —es decir, orientado al mantenimiento de la vida en el tejido-mundo-, para lo cual cuenta con distintos modos del conocer, entre los que señalamos tres conceptos-prácticas del vivir: el medir la mano, el fortalecer el manejo de los aires de aliento y el encontrar el propio cuerpo.

En estas circunstancias, el "saber enfrentar la vida" implica, la asunción del flujo vital entre los interlocutores-gentes humanos y no humanos, desde la visibilización de la responsabilidad humana en los modos del conocer, en la interacción consecuente entre lo individual y lo comunitario, y en el equilibrio de las fuerzas vitales que configuran a las personas, a las sociedades y a los pueblos, mediante la realización precisa y pertinente de las acciones necesarias para la existencia.

Haciendo parte de la institución universitaria, y situados simultáneamente como exterioridades relativas al orden del eurocentrismo, señalamos la pertinencia del diálogo intercultural con miradas, voces y experiencias vitales, como las que son enunciadas en el conocimiento-sensible uitoto, hacia la construcción de modos "otros" de la relación sensible, desde el respeto a la naturaleza, el reconocimiento mutuo entre los seres, personas, gentes y pueblos; y la generación de modos de existencia humana orientados al mantenimiento de la vida. Tal vez, mediando el enraizamiento en nuestras ascendencias y memorias, el tejido de nuestras historias en comunidad y nuestra visibilización como sujetos de conocimiento y de transformación personal, social y política en el interés comunitario; podamos escuchar lo que tiene que decir la lagartija roja, respecto a las formas del vivir humano cimentadas en el poder de la armonía, en el reconocimiento entre nuestros padres y madres, en el diálogo entre conocimientos y sensibilidades, y en el encuentro de nuestros "propios cuerpos", como parte de la descolonización en lo sensible.

\section{Referencias}

Albán, Adolfo (2009). "Artistas indígenas y afrocolombianos: entre las memorias y las cosmovisiones. Estéticas de la Re-existencia" en Z. Palermo, Arte y Estética en la encrucijada descolonial (págs. 83-113). Buenos Aires, Argentina: Del Signo.

Castro-Gómez, S., Guardiola-Rivera y Millán de Benavides. (1999). Pensar en los intersticios. Teoría y práctica de la crítica poscolonial. Bogotá: Colección Pensar.

Castro-Gómez, S. (2005). La hybris del punto cero: Ciencia, raza e ilustración en la Nueva Granada (1750- 1816). Bogotá: Editorial Pontificia Universidad Javeriana.

Corredor, A. (2017). “¿Azul-verde de qué? (Minica Mokorede)" en Calle 14 Revista De investigación En El Campo Del Arte, 12(21), 114-125. Disponible en https://doi.org/10.14483/21450706.11902

De Corredor, Blanca (1986). La Maloca. Monografía. 1. Bogotá, Colombia: Universidad Nacional de Colombia.

Grosfóguel, Ramón y Castro-Gómez, Santiago (2007). "Introducción" en El Giro decolonial. Reflexiones para una diversidad epistémica más allá del capitalismo global. Bogotá: Pontificia Universidad Javeriana.

Quijano, Aníbal (1999). “Colonialidad del poder, cultura y conocimiento en América Latina" en S. Castro-Gómez, O. Guardiola-Rivera, C. Millán (editores). Pensar (en) los intersticios. Teoría y práctica de la crítica poscolonial. Bogotá: Colecciones Pensar/ Pontificia Universidad Javeriana.

Maldonado-Torres, Nelson. (2007). "Sobre la colonialidad del ser: contribuciones al desarrollo de un concepto" en El giro Decolonial. Reflexiones para una diversidad epistémica más allá del capitalismo global, Santiago Castro Gómez y Ramón Grosfoguel ed. Bogotá: Siglo del Hombre editores.

Mignolo, W., y Walsh, C. (2002). "Las geopolíticas del conocimiento y colonialidad del poder", en Walsh, Freya Schiwi y Santiago Castro, Indisciplinar las ciencias sociales. Geopolítica del conocimiento y colonialidad del poder. Perspectivas desde lo andino. Quito: UASB, ediciones Abya-Yala. 
Mignolo, Walter (2010) "Aiesthesis decolonial" en Revista Calle 14, Bogotá, volumen 4, número 4, enero junio de 2010: 13.

(septiembre de 2011). Geopolítica de la sensibilidad y del conocimiento Sobre (de)colonialidad, pensamiento fronterizo y desobediencia epistémica. Disponible en http://eipcp.net/transversal/0112/mignolo/es (s.f) "El desprendimiento", traducido por José Romero, Caracas. Copia digital.

Román, Isaías (12 de diciembre de 2009). Diálogo con Andrés Corredor. Historia de Jitoma. Bogotá. (30 de enero de 2010). Diálogo con Andrés Corredor. Clasificación de las Gentes. Bogotá. (20 de febrero de 2010a). Diálogo con Andrés Corredor. Somos Naturaleza, de la Clasificación de las gentes. Bogotá, Colombia.

(20 de junio de 2010b). Diálogo con Andrés Corredor. Sobre la educación. Bogotá.

(7 de octubre de 2011). Diálogo con Andrés Corredor. Sentarse para el conocimiento. Bogotá.

(24 de julio de 2012). Diálogo con Andrés

Corredor. Sembrar. Bogotá.

(17 de noviembre de 2012a). Diálogo con Andrés Corredor. Saber comer, saber sembrar. Bogotá.
(12 de diciembre de 2012b). Diálogo con Andrés Corredor. Sensibilidad, Ser Sensible.

(16 de mayo de 2013). Diálogo con Andrés Corredor. Jitoma, Jaigüenikt - Huérfano. Bogotá.

(20 de junio de 2013a). Diálogo con Andrés

Corredor. Comentario final sobre las pinturas de La Mirada del Colibrí. Bogotá.

(29 de agosto de 2013b). Diálogo con

Andrés Corredor. Canciones de Cuatro Carreras

Ceremoniales, para la Mirada del Colibrí. Bogotá.

Sánchez, Alicia (1990). Diálogo con Andrés Corredor. Cuento de Jitoma. Bogotá.

Pineda Camacho, R. (2000). Holocausto en el Amazonas. Una historia social de la casa Arana. Bogotá: Planeta Colombiana Editorial.

Vargas Tovar, C. (Ed.). (2012). Informe "Contribuciones locales a una historia de la minería en la Amazonia colombiana".

Walsh, C, (2010). Interculturalidad crítica y educación intercultural. (CAB, Ed.) Recuperado el 27 de julio de 2014, de Construyendo Interculturalidad Crítica. Disponible en https://tinyurl.com/y6btxwek 